\title{
Amplification of tsunami heights by delayed rupture of great earthquakes along the Nankai trough
}

\author{
Kentaro Imai $^{1,2}$, Kenji Satake ${ }^{2}$, and Takashi Furumura ${ }^{1,2}$ \\ ${ }^{1}$ Center for Integrated Disaster Information Research, Interfaculty Initiative in Information Studies, \\ Graduate School of Interdisciplinary Information Studies, The University of Tokyo, \\ 7-3-1 Hongo, Bunkyo-ku, Tokyo 113-0033, Japan \\ ${ }^{2}$ Earthquake Research Institute, The University of Tokyo, 1-1-1 Yayoi, Bunkyo-ku, Tokyo 113-0032, Japan
}

(Received March 16, 2009; Revised November 20, 2009; Accepted December 18, 2009; Online published June 17, 2010)

\begin{abstract}
We investigated the effect of delayed rupture of great earthquakes along the Nankai trough on tsunami heights on the Japanese coast. As the tsunami source, we used a model of the 1707 Hoei earthquake, which consists of four segments: Tokai, Tonankai, and two Nankai segments. We first searched for the worst case, in terms of coastal tsunami heights, of rupture delay time on each segment, on the basis of superposition principle for the linear long wave theory. When the rupture starts on the Tonankai segment, followed by rupture on the Tokai segment 21 min later, as well as the eastern and western Nankai segments 15 and 28 min later, respectively, the average coastal tsunami height becomes the largest. To quantify the tsunami amplification, we compared the coastal tsunami heights from the delayed rupture with those from the simultaneous rupture model. Along the coasts of the sea of Hyu'uga and in the Bungo Channel, the tsunami heights become significantly amplified ( $>1.4$ times larger) relative to the simultaneous rupture. Along the coasts of Tosa Bay and in the Kii Channel, the tsunami heights become amplified about 1.2 times. Along the coasts of the sea of Kumano and Ise Bay, and the western Enshu coast, the tsunami heights become slightly smaller for the delayed rupture. Along the eastern Enshu coast, the coast of Suruga Bay, and the west coast of Sagami Bay, the tsunami heights become amplified about 1.1 times.
\end{abstract}

Key words: Nankai trough, great earthquakes, tsunami, delayed rupture, tsunami height.

\section{Introduction}

Great earthquakes (moment magnitude $M_{\mathrm{w}}>8$ ) have recurred along the Nankai trough with an interval of approximately 100 years. The source areas of these earthquakes consist of four segments: Tokai (N1), Tonankai (N2) and two Nankai (N3 and N4) segments (Fig. 1). The rupture history on these segments has been estimated from Japanese historical documents. Figure 1 shows recurrence of historical earthquakes along the Nankai trough. Many earthquakes have been documented since the 684 Hakuho event. For older earthquakes occurred before the Edo period (started 1603), the estimated source areas have some ambiguity (shown in dashed lines), because of limited historical documents.

The 1707 Hoei earthquake was one of the largest earthquakes occurred in Edo period, when historical documents had become available throughout Japan. This earthquake resulted $M_{\mathrm{w}}$ over 8.4 and the tsunami runup heights more than $5 \mathrm{~m}$ on the Pacific coast. For this event, the rupture is considered to have started from the N2 segment and all the (N1 to N4) segments were broken with short time delay. However, based on historical documents, some studies claimed that time delay of less than several tens of minutes

Copyright (c) The Society of Geomagnetism and Earth, Planetary and Space Sciences (SGEPSS); The Seismological Society of Japan; The Volcanological Society of Japan; The Geodetic Society of Japan; The Japanese Society for Planetary Sciences; TERRAPUB.

doi:10.5047/eps.2009.12.005 might exist between fault rupture at each segment during the 1707 Hoei earthquake (Iida, 1985; Usami, 2003). Such delayed rupture between segments would produce positive interference of tsunami amplitude and duration compared with simultaneous rupture, hence important for mitigating tsunami disasters associated with the Nankai trough earthquakes.

The effect of such rupture delay on coastal tsunami heights was studied by Kawata et al. (2003), and also by Central Disaster Mitigation Council (http://www.bousai. go.jp/jishin/chubou/nankai/16/sankousiryou2_9.pdf). They evaluated, based on the superposition principle for the linear long wave theory, the tsunami heights at 10 local points such as Shizuoka, Nagoya and Wakayama. They simply considered the worst case for each of evaluation points without considering seismological or geophysical rupture scenarios. Evaluation of tsunami heights based on the superposition principle is simple and efficient; however, there is a possibility to overestimate the tsunami heights by using linear long wave equation without considering the effects of bottom friction or advection terms.

In addition to the historical records of past earthquakes, geophysical modeling supports the nucleation of large earthquakes from the Tonankai (N2) segment off Kii Peninsula. Hori et al. (2004) made numerical simulation of cyclic occurrence of large earthquakes along the Nankai trough and showed that large earthquakes nucleate off Kii Peninsula, where both dip angle and the convergence rate of the 


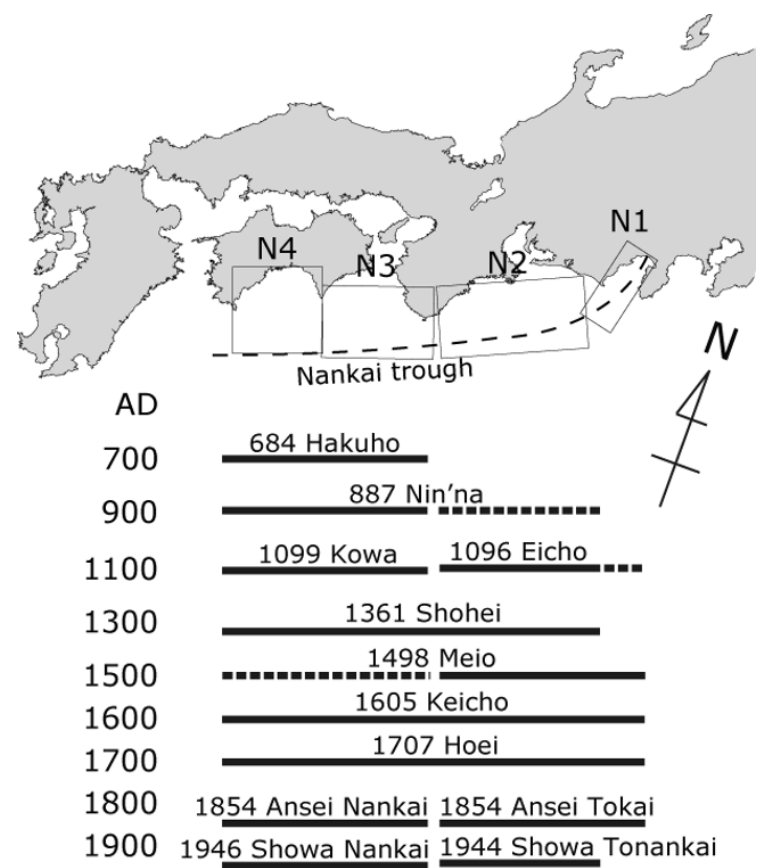

Fig. 1. Historical earthquakes along the Nankai trough (Usami, 2003; Ishibashi, 2004) The solid and dashed lines indicate confirmed and speculated sources areas from studies of historical documents.

subducting slab are larger than the other segments.

In this paper, we investigate the effects of delayed rupture of the Nankai and Tokai segments, based on a seismological model by assuming that the rupture initiates at the Tonankai (N2) segment off Kii Peninsula. We first search for the worst case of rupture delay in terms of coastal tsunami heights based on the superposition principle for the linear long wave theory. We then make tsunami simulation of nonlinear long wave theory for the worst case scenario, to examine the amplification of tsunami heights relative to the simultaneous rupture on the coasts from Sagami Bay through Kyushu.

\section{Numerical Computation}

Tsunami simulation is carried out by using finite difference method with staggered leap frog scheme (Goto and Ogawa, 1997). The nonlinear long wave equations are expressed as

$$
\begin{gathered}
\frac{\partial \eta}{\partial t}+\frac{\partial M}{\partial x}+\frac{\partial N}{\partial y}=0 \\
\frac{\partial M}{\partial t}+\frac{\partial}{\partial x}\left(\frac{M^{2}}{D}\right)+\frac{\partial}{\partial y}\left(\frac{M N}{D}\right)+g D \frac{\partial \eta}{\partial x} \\
+\frac{g n^{2}}{D^{7 / 3}} M \sqrt{M^{2}+N^{2}}=0 \\
\frac{\partial N}{\partial t}+\frac{\partial}{\partial x}\left(\frac{M N}{D}\right)+\frac{\partial}{\partial y}\left(\frac{N^{2}}{D}\right)+g D \frac{\partial \eta}{\partial x} \\
+\frac{g n^{2}}{D^{7 / 3}} N \sqrt{M^{2}+N^{2}}=0
\end{gathered}
$$

where $\eta$ is wave amplitude, $D$ is total depth, $M$ and $N$ are flux discharge in two horizontal directions, $g$ is gravity acceleration, and $n$ is Manning's roughness coefficient

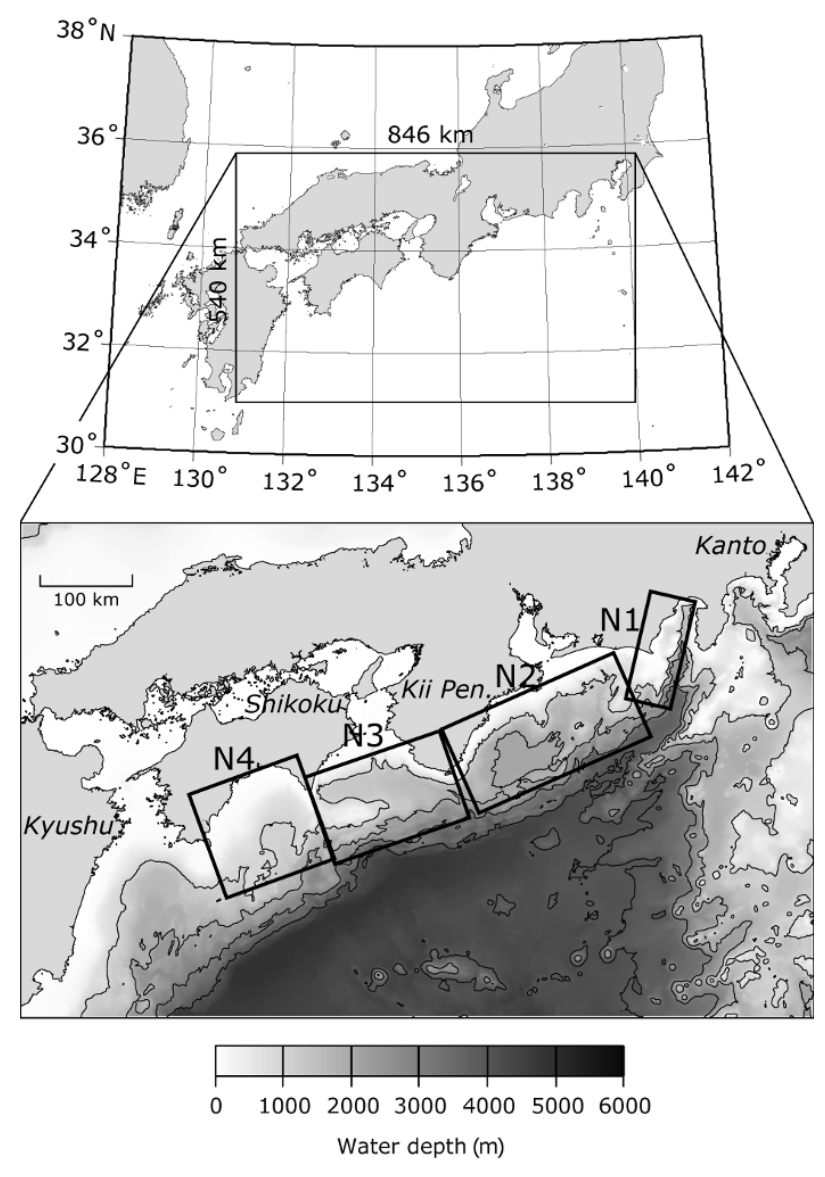

Fig. 2. Computational region. The four segments, N1 to N4, are shown. The contour interval of bathymetry data is $1000 \mathrm{~m}$.

Table 1. Fault parameter of the 1707 Hoei earthquake (Annaka et al., 2003).

\begin{tabular}{cccccccccc}
\hline Seg. No. & $\begin{array}{c}\text { Fault locaton } \\
\text { Lat. }(\mathrm{N}) \text { Lon. }(\mathrm{E})\end{array}$ & \multicolumn{2}{c}{$\begin{array}{c}\text { Length Width } \\
(\mathrm{km})\end{array}$} & $\begin{array}{c}\text { Depth } \\
(\mathrm{km})\end{array}$ & $\begin{array}{c}\text { Strike Dip } \\
(\mathrm{km})\end{array}$ & & & Rake & $\begin{array}{c}\text { Slip } \\
(\mathrm{m})\end{array}$ \\
\hline $\mathrm{N} 1$ & $35.120^{\circ}$ & $138.706^{\circ}$ & 120 & 50 & 6.4 & $193^{\circ}$ & $20^{\circ}$ & $71^{\circ}$ & 5.6 \\
$\mathrm{~N} 2$ & $33.823^{\circ} 138.235^{\circ}$ & 205 & 100 & 4.1 & $246^{\circ}$ & $10^{\circ}$ & $113^{\circ}$ & 7.0 \\
$\mathrm{~N} 3$ & $33.006^{\circ} 136.074^{\circ}$ & 155 & 100 & 7.8 & $251^{\circ}$ & $12^{\circ}$ & $113^{\circ}$ & 5.6 \\
$\mathrm{~N} 4$ & $32.614^{\circ} 134.481^{\circ}$ & 125 & 120 & 10.1 & $250^{\circ}$ & $8^{\circ}$ & $113^{\circ}$ & 9.2 \\
\hline
\end{tabular}

Fault location is at northeast corner of each segment. Depth is measured from seafloor.

$\left(0.025 \mathrm{~m}^{-1 / 3} \mathrm{~s}\right.$ in the sea and $0.03 \mathrm{~m}^{-1 / 3} \mathrm{~s}$ on land $)$. The computational region (Fig. 2) extends from Kanto to Kyushu, with the grid size of $270 \mathrm{~m}$. The computational time interval is $0.6 \mathrm{~s}$ to satisfy the stability condition of the finite difference method.

For the tsunami source, we adopt the 1707 Hoei earthquake model by Annaka et al. (2003), which consists of four fault segments (N1 to N4) along the plate boundary between the Eurasian plate and the Philippine Sea plate. This model reproduces distribution of the actual tsunami heights better than previous models (e.g., Ando, 1975; Aida, 1981). The surface displacement is calculated by using the method of Mansinha and Smylie (1971), and the surface displacement is assumed to accomplish in $60 \mathrm{~s}$. Table 1 shows the fault parameter and Fig. 3 shows the surface displacement. 


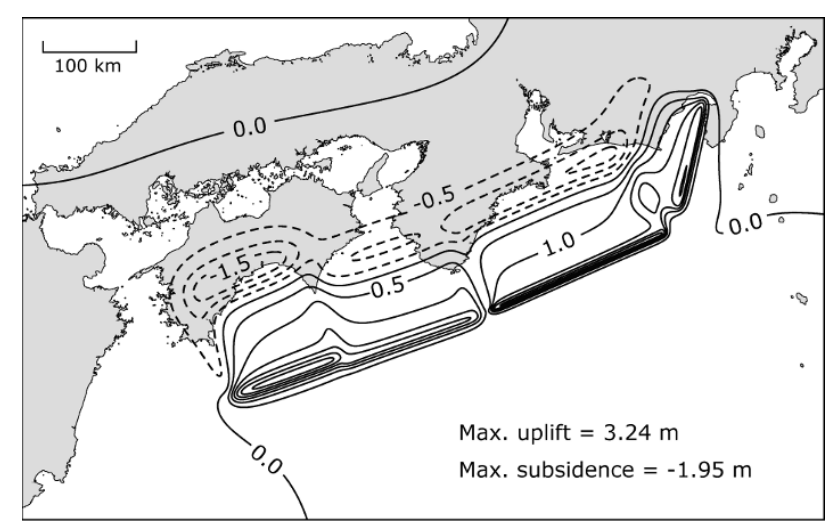

Fig. 3. Surface displacement of the 1707 Hoei earthquake (Annaka et al., 2003). The solid line shows uplift, and the dashed line shows subsidence with contour interval of $0.5 \mathrm{~m}$.

\section{Search for the Worst Case of Rupture Delay}

We calculate tsunami heights at 36 coastal points (Fig. 4) for short rupture delay, based on the superposition principle for linear long wave equation. The linear long wave equation corresponds to drop the advection (2nd and 3rd) terms and the bottom friction (5th) term in Eqs. (2) and (3). Water depth of $10 \mathrm{~m}$ or less is replaced with $10 \mathrm{~m}$, and a vertical wall is set up on the shore line for the total reflection at the coastal boundary. We examined the effects of rupture velocity within each segment by varying the velocity from 1.5 to $3.0 \mathrm{~km} / \mathrm{s}$ and found that the coastal heights were very similar to the simultaneous rupture. Therefore, we assume that rupture within each segment is simultaneous.

The rupture delay time for each segment is searched under three conditions based on the seismological and geophysical information; 1) the rupture starts on the N2 segment, 2) the delay time is less than 60 min on neighboring segments, and 3) rupture on the N4 segment is followed by that on the N3 segment. The tsunami waveform at each local point is evaluated based on the superposition principle. The maximum tsunami height is searched with 1 min interval for $120 \mathrm{~min}$ from the initial rupture of the N2 segment.

Examples of synthetic tsunami waveform for the simultaneous and delayed rupture are shown in Fig. 5. Synthetic tsunami waveform for the simultaneous rupture is computed by simply summing the waveforms calculated from the N1 to N4 segments. By varying rupture delay on each segment, the synthetic waveforms have larger maximum amplitudes, as shown in dashed lines in the figure.

At Susaki on the coast of Tosa Bay, the synthetic waveform is dominated by waveforms from the N4 and N3 segments, and the contribution from the N1 and N2 segments is small. Because Susaki is located far from the N1 and N2 segments, the delayed rupture on the N1 segment has little effect on the synthetic waveform. The same feature is seen on the coasts of the sea of Hyu'uga, in the Bungo Channel, of Tosa Bay and in the Kii Channel.

At Kumano in Kii Peninsula, amplitudes of tsunami waveforms from the four segments are similar. Because the initial part of the synthetic waveform, including the maximum amplitude, is controlled by the waveform from the N2 segment, the delayed rupture on the other segments has lit-

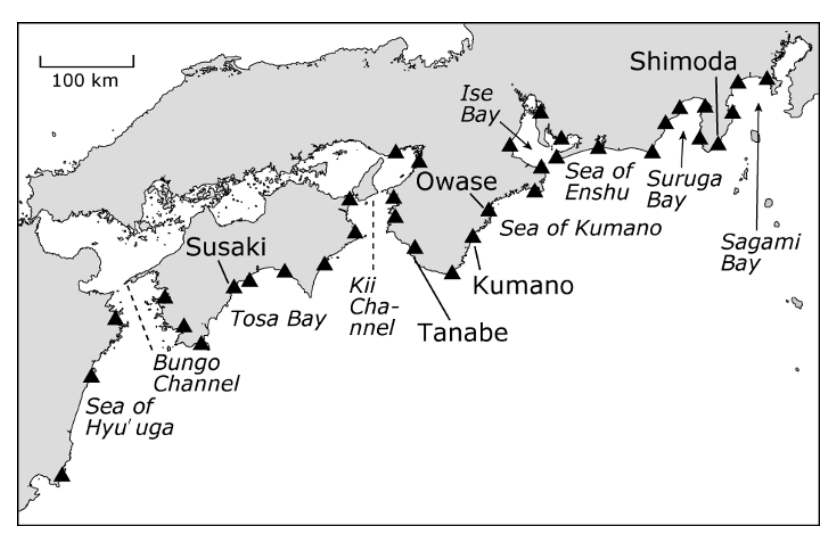

Fig. 4. Distribution of output points (triangles).

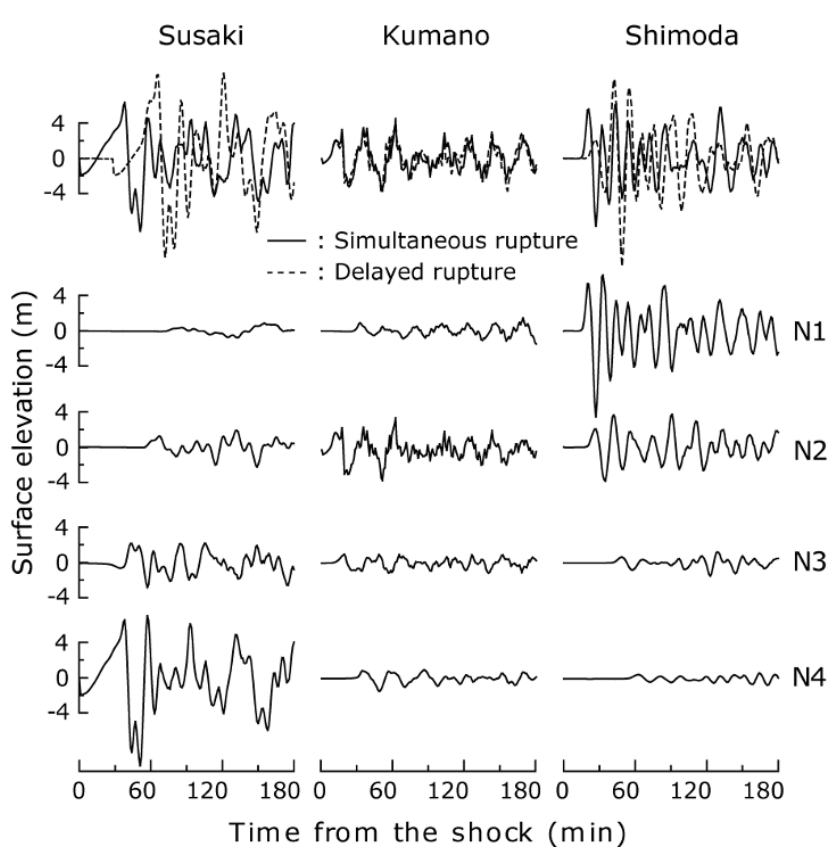

Fig. 5. Synthetic tsunami waveform (top). The solid line shows waveform for the simultaneous rupture, and the dashed line shows waveform for the delayed rupture. Waveforms from the four segments (without delay) are also shown.

Table 2. Rupture delay time of the worst case scenario.

\begin{tabular}{cc}
\hline Seg. No. & Rupture delay time $(\mathrm{min})$ \\
\hline N1 & 21 \\
N2 & 0 \\
N3 & 15 \\
N4 & 28 \\
\hline
\end{tabular}

tle effect on the maximum amplitude. The same feature is seen on the other coasts facing to the N2 segment, i.e., the coast of the sea of Kumano, the coast of Ise Bay and the western Enshu coast.

At Shimoda in Izu Peninsula, the waveform from the N1 segment has the largest contribution, followed by that from the N2 segment, to the synthetic waveform. By delaying the N1 waveform, the synthetic waveform has larger amplitude 
than the simultaneous rupture. The same feature is seen on the eastern Enshu coast, on the coast of Suruga Bay, and on the west coast of Sagami Bay.

To quantify the amplification of coastal tsunami heights with respect to the simultaneous rupture, we introduce geometric average $A$ of the ratios of computed tsunami heights from the delayed rupture to that from the simultaneous rupture at 36 points. Computed coastal heights less than $0.5 \mathrm{~m}$ are excluded for the calculation of $A$ value.

We search for a combination of rupture delay times on the N1, N3 and N4 segments, which makes the amplitude of synthetic tsunami waveforms maximum. We vary the rupture delay times up to $60 \mathrm{~min}$ for $1 \mathrm{~min}$ interval, hence we examined $60 * 60 * 60$ cases to find the maximum value.

The combination that gives the maximum $A$ value is shown in Table 2. The $A$ value is 1.26 for this worst case. Unlike the previous scenario (Kawata et al., 2003), this scenario is based on seismological studies and considered to be realistic rather than a purely worst case scenario.

\section{Nonlinear Computation for the Rupture Sce- nario}

The search made in the last section indicates that the rupture scenario shown in Table 2 produces the largest tsunami heights on the average. Because we assumed the superposition principle for the linear long waves, there is a possibility to have overestimated tsunami heights without considering the effects of bottom friction and advection terms. We therefore calculate the coastal tsunami heights for the above scenario by using nonlinear long wave theory.

Figure 6 shows a comparison of linear and nonlinear tsunami waveforms for the above rupture scenario. At Tanabe, the maximum amplitude appears at about $300 \mathrm{~min}$ for the linear and nonlinear computations, but the amplitude becomes smaller in the nonlinear computation. At Owase, the linear computation shows the maximum amplitude in the third wave at around $60 \mathrm{~min}$, but the amplitude becomes smaller in the nonlinear computation, making the first wave the largest. The value of $A$ for 36 local points is 1.27 for the nonlinear long wave computation, very similar to the linear case. While the absolute values of computed tsunami

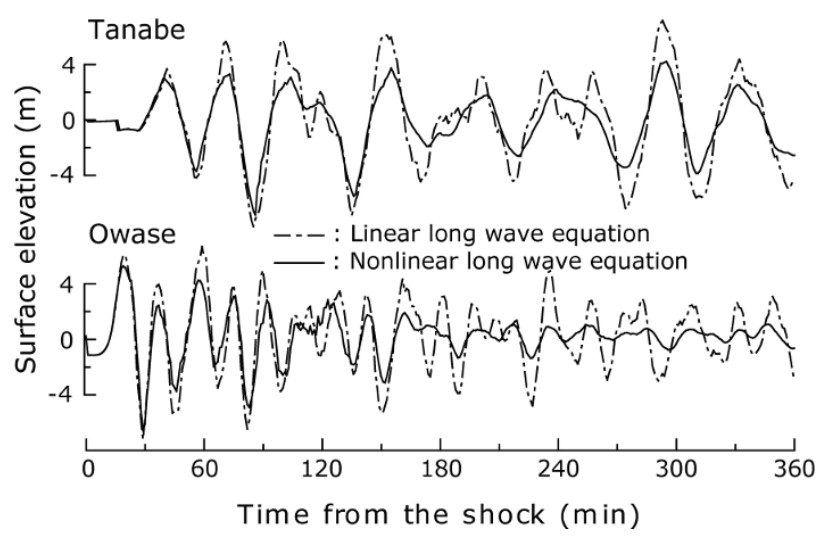

Fig. 6. Comparison of waveforms computed for the worst-case scenario of rupture delay. The dash-dot line shows waveform for the linear long wave equation, and the solid line shows waveform for nonlinear long wave equation. heights are different for the linear and nonlinear cases, the ratio of computed tsunami heights from delayed and simultaneous ruptures are similar. Therefore, it is expected the worst scenario estimated from the linear long wave computation also yields the worst scenario for the nonlinear case.

\section{Tsunami Heights Along the Japanese Coast}

We calculate the coastal tsunami heights from the worst case scenario and compare them with those from the simultaneous rupture. Figure 7 shows distribution of maximum tsunami heights along the Japanese coast for the simultaneous and delayed ruptures. On the basis of the relative heights of simultaneous and delayed ruptures, the $A$ value for the Japanese coast is 1.13 for the nonlinear long wave computation, which is slightly larger than 1.09 for the linear long wave equation. However, amplification of the tsunami heights varies from coast to coast. Therefore, it is necessary to evaluate the $A$ value for each coast. Depending on the $A$ value, the coasts are grouped into four types, Coasts 1 through 4.

Along Coast 1, the east coast of Kyushu (1-1) and the coast in the Bungo Channel $(1-2,3)$, tsunami heights in most of the coastline are significantly amplified $(A>1.4)$ for the delayed rupture scenario. As we have seen in Fig. 5, the tsunami from the delayed ruptures of the N3 and N4 segments interferes with the westward propagating tsunami from the N2 segment to cause larger amplitudes. But the delayed rupture on the $\mathrm{N} 1$ segment has little effect on the tsunami height.

Along Coast 2, the coast of Tosa Bay (2-1) and the west (2-2) and east $(2-3,4)$ coasts in the Kii Channel, tsunami heights in most of the coastline are amplified for the delayed rupture scenario $(1<A<1.2)$. At some locations around Susaki, Kaifu and Tanabe, the tsunami heights for the delayed rupture become very large.

Along Coast 3, the coast of the sea of Kumano (3-1), and close to Ise Bay $(3-2,3)$ and the western Enshu coast (34), the tsunami heights for the delayed rupture scenario are similar to $(3-1,2,3, A \sim 1)$ or smaller than $(3-4, A<1)$ the simultaneous rupture. Maximum tsunami heights on Coast 3-1, 3-2 and 3-3 are controlled by the N2 segment, hence the delayed rupture on the other segments has little effect on the maximum tsunami heights. Tsunami heights on Coast 3-4 are controlled by both $\mathrm{N} 1$ and $\mathrm{N} 2$ segments; tsunamis from these segments arrive almost the same time to amplify the coastal heights.

Along Coast 4, the eastern Enshu coast and the coast of Suruga Bay (4-1), and the west coast of Sagami Bay (4$2)$, tsunami heights for the delayed rupture scenario become larger than the simultaneous rupture $(1<A<1.2)$, particularly around Omaesaki and Irouzaki. These amplifications of tsunami heights are due to delayed rupture on the N1 segment as we have seen in Fig. 5. On the coast east of Ito, the heights are almost the same for the simultaneous and delayed ruptures.

\section{Conclusion}

We investigated the effects of delayed rupture of the Tokai and Nankai segments on coastal tsunami heights. The parameter search based on the superposition principle of 

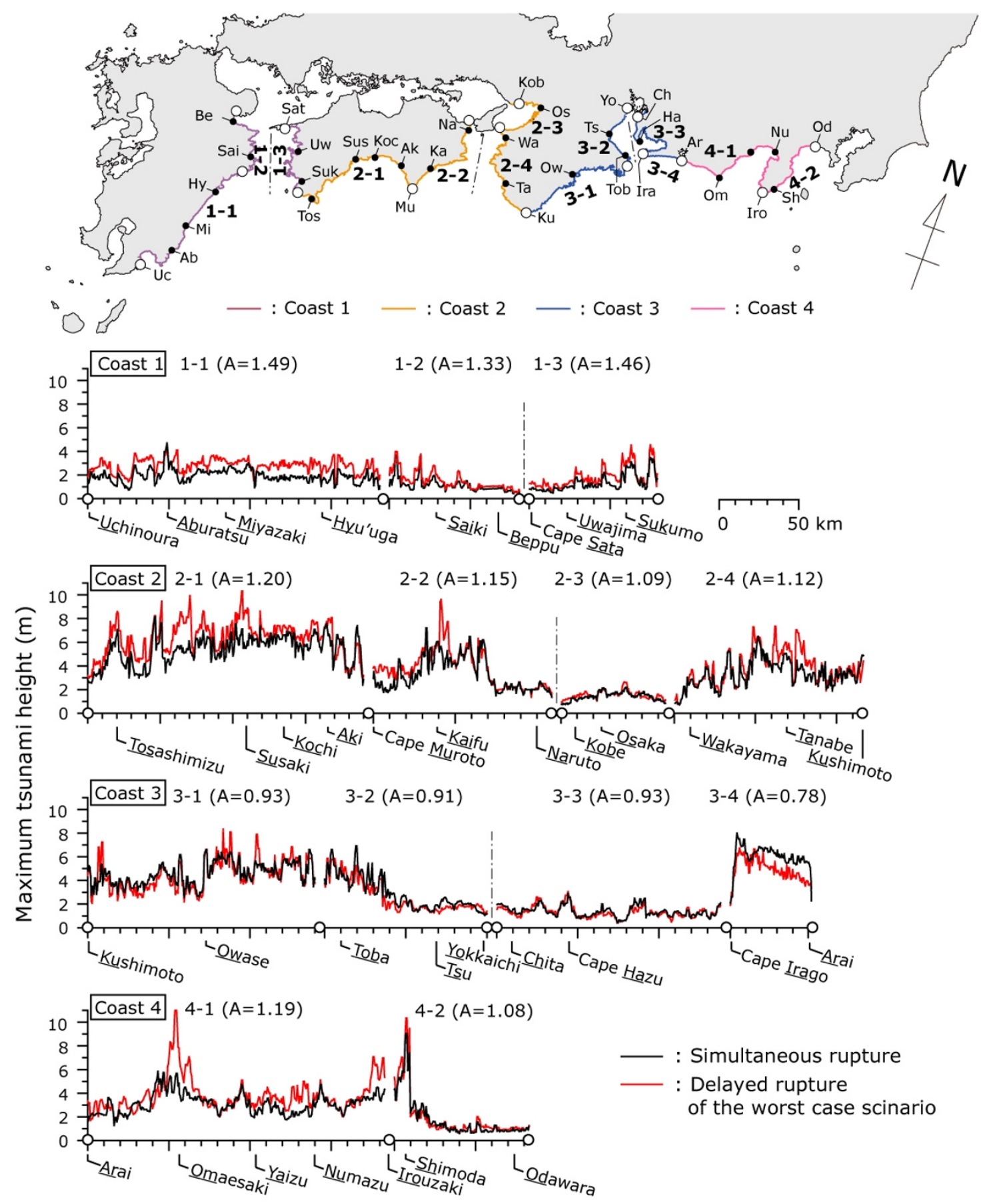

Distance along coast $(\mathrm{km})$

Fig. 7. Distribution of maximum tsunami heights along the Japanese coast. Upper map shows the Japan's Pacific coast with categorized coast line type. Black circles indicate representative locations (see lower figures for the full names). Lower figures show distributions of maximum tsunami heights computed above M.S.L. Open circles indicate dividing points of categorized coastline type.

linear long wave theory indicates that the worst case scenario is the rupture starts on the Tonankai (N2) segment followed by the rupture on the Tokai (N1) segment $21 \mathrm{~min}$ later, and the Nankai (N3 and N4) segments 15 min and 28 min later. In this scenario, the tsunami heights become significantly amplified $(A>1.4)$ with respect to the simultaneous rupture along the coasts of the sea of Hyu'uga and in the Bungo Channel, amplified $(1<A<1.2)$ along the coasts of Tosa Bay and in the Kii Channel. The tsunami heights are similar $(A \sim 1)$ along the coasts of the sea of
Kumano and of Ise Bay, and smaller $(A<1)$ along the western Enshu coast. Along the coast of Suruga Bay and along the west coast of Sagami Bay, the tsunami heights become amplified $(1<A<1.2)$.

Acknowledgments. This study was supported by Research Project of the "Improvements of strong ground motion and tsunami simulation accuracy for application of realistic disaster prevention of the Nankai-Trough mega-thrust earthquake" of the Ministry of Education, Culture and Sports, Science and Technology. Bathymetry data in this study was offered by the Cabinet 
Office. We are grateful to Drs. Tatsuhiko Saito of ERI, Univ. of Tokyo and Yuichi Namegaya of AIST for their advice during the course of this study.

\section{References}

Aida, I., Numerical experiments for the tsunamis generated off the coast of the Nankaido district, Bull. Earthq. Res. Inst., 56, 713-730, 1981 (in Japanese).

Ando, M., Source mechanisms and tectonic significance of historical earthquakes along the Nankai trough, Japan, Tectonophysics, 27, 204-215, 1975.

Annaka, T., K. Inagaki, H. Tanaka, and K. Yanagisawa, Characteristics of great earthquakes along the Nankai trough based on numerical tsunami simulation, J. Earthq. Eng., JSCE, CD-ROM, 2003 (in Japanese).

Goto, C. and Y. Ogawa, (IUGG/IOC TIME PROJECT), Numerical method of tsunami simulation with the leap-frog scheme, Part 1 Shallow water theory and its difference scheme, Intergovernmental Oceanographic Commission, Manuals and Guides, No. 35, 43 p., 1997.

Hori, T., N. Kato, K. Hirahara, T. Baba, and Y. Kaneda, A numerical simulation of earthquake cycles along the Nankai trough, southwest Japan: Lateral variation in frictional property due to the slab geometry controls the nucleation position, Earth Planet. Sci. Lett., 228, 215-226, 2004.

Iida, K., Investigation of historical earthquakes (5): Earthquake and tsunami damages by the Hoei earthquake of October 28, 1707, Bull. Aichi Inst. Technol. Part B, 17, 143-157, 1985 (in Japanese).

Ishibashi, K., Status of historical seismology in Japan, Ann. Geophys., 47, 339-368, 2004.

Kawata, Y., S. Suzuki, and T. Takahashi, An effect of giant earthquake scenarios at the Nankai trough on a tsunami hazard, Proc. Coastal Eng., JSCE, 50, 326-330, 2003 (in Japanese).

Mansinha, L. and D. E. Smylie, The displacement fields of inclined faults, Bull. Seismol. Soc. Am., 61(5), 1433-1440, 1971.

Usami, T., Materials for Comprehensive List of Destructive Earthquakes in Japan, University of Tokyo Press, 2003 (in Japanese).

K. Imai (e-mail: imai@eri.u-tokyo.ac.jp), K. Satake, and T. Furumura 